\title{
Ocorrência de Colletotrichum gloeosporioides em Tapeinochilus ananassae no estado de Alagoas
}

\author{
Daniela Cavalcanti de Medeiros Furtado, ${ }^{1,2}$; André Luiz Beserra Galvão ${ }^{1,2}$; Edna Peixoto da Rocha Amorim ${ }^{1,3}$; Julio \\ Cesar da Silva"; Laís Peixoto da Rocha Soares ${ }^{5}$.
}

\begin{abstract}
${ }^{1}$ Universidade Federal de Alagoas; ${ }^{2}$ Prof ${ }^{\circ}$ Assistente - Campus Arapiraca, Caixa Postal 61, CEP 57300-970, Arapiraca, AL; ${ }^{3}$ Prof ${ }^{a}$ Associada-Centro de Ciências Agrárias CECA/UFAL, Rio Largo, AL, CEP57100-000; ${ }^{4}$ Engenheiro Agrônomo, Doutorando em Proteção de plantas, UNESP- Universidade Estadual Paulista, Botucatu-SP. ${ }^{5}$ Engenheira Agrônoma, Mestranda em Horticultura, UNESP- Universidade Estadual Paulista, Botucatu-SP. Autor para correspondência: Daniela Cavalcanti de Medeiros Furtado (furtado_dcm@yahoo.com) Data de chegada: 13/06/2012. Aceito para publicação em: 09/11/2012.
\end{abstract}

Tapeinochilus ananassae Hassk, também conhecida como Tapeinóchilo, gengibre abacaxi ou gengibre da Indonésia, é uma planta da Ordem Zingiberales, família Costaceae, encontra-se entre as plantas ornamentais tropicais cultivadas como ornamental para jardins e uso em decoração de interiores. Atualmente tem sido cultivada por diversos produtores, para uso como flor de corte. Dentre as doenças de origem fúngica que afetam as flores tropicais está à antracnose, causada por fungo do gênero Colletotrichum, destacando-se pela ocorrência comum e pelos danos que causam às plantas.

A ocorrência de sintomas é observada nas brácteas, onde há a presença de lesões encharcadas, seguidas de necrose de coloração escura que coalescem e evoluem para podridão generalizada, ocupando grandes áreas dos tecidos florais de T. ananassae (Figura 1A).

$\mathrm{O}$ objetivo deste trabalho foi identificar o agente causal de mancha em inflorescências de T. ananassae no estado de Alagoas.

Inflorescências infectadas, com os sintomas típicos de antracnose, foram levadas ao laboratório, plaqueando fragmentos de brácteas desinfestados em meio de batata-dextrose-ágar (BDA), posteriormente mantidos a $25^{\circ} \mathrm{C}$, em fotoperíodo de $12 / 12$ horas claro/escuro. A colônia e os conídios mostraram-se típicos do fungo do gênero Colletotrichum spp.

A patogenicidade do isolado obtido foi efetuada em inflorescências previamente limpas e desinfestadas em hipoclorito de sódio a $2 \%$. Discos de BDA, contendo micélio do patógeno, foram inseridos em incisões efetuados nas brácteas das inflorescências. As testemunhas receberam discos de meio de cultura, sem o patógeno utilizando-se a mesma metodologia. As plantas inoculadas e as testemunhas foram mantidas em câmera úmida por 48 horas, à temperatura ambiente.

As inflorescências inoculadas com o isolado apresentaram sintomas de necrose das brácteas cinco dias após a inoculação. Enquanto as testemunhas permaneceram sadias. Do material doente, procedeu-se isolamento em meio BDA e confrontando-se as colônias originais com a do reisolado quanto à semelhança, confirmando-se a patogenicidade do isolado.

A identificação do patógeno foi realizada, respectivamente, através de observações na morfologia e dimensão das estruturas reprodutivas. As dimensões das estruturas foram obtidas por meio de 100 observações das estruturas reprodutivas do patógeno. Os conídios do fungo apresentaramse hialinos, unicelulares, retos com paredes finas, elipsóides a cilíndricos, obtusos no ápice e de dimensões iguais a 6,64 - 16,6 x 1,66 - 3,32 $\mu \mathrm{m}(\mathrm{X}=$ $12,29 \times 2,66 \mu \mathrm{m})$. O mesmo foi identificado como Colletotrichum gloeosporioides (SUTTON (1980)*.

Este é o primeiro relato no Estado de Alagoas, de C. gloeosporioides (Penz.) Penz. \& Sacc em inflorescências de T. ananassae. Porém, no Estado de Pernambuco há relato do patógeno na forma teleomorfa, Glomerella cingulata (Stonem.) Spauld. \& Schrenk., causando manchas foliares em T. ananassae .

*SUTTON, B.C. The Coelomycetes. Kew: Commonwealth Mycological Institute, 1980. 696p.
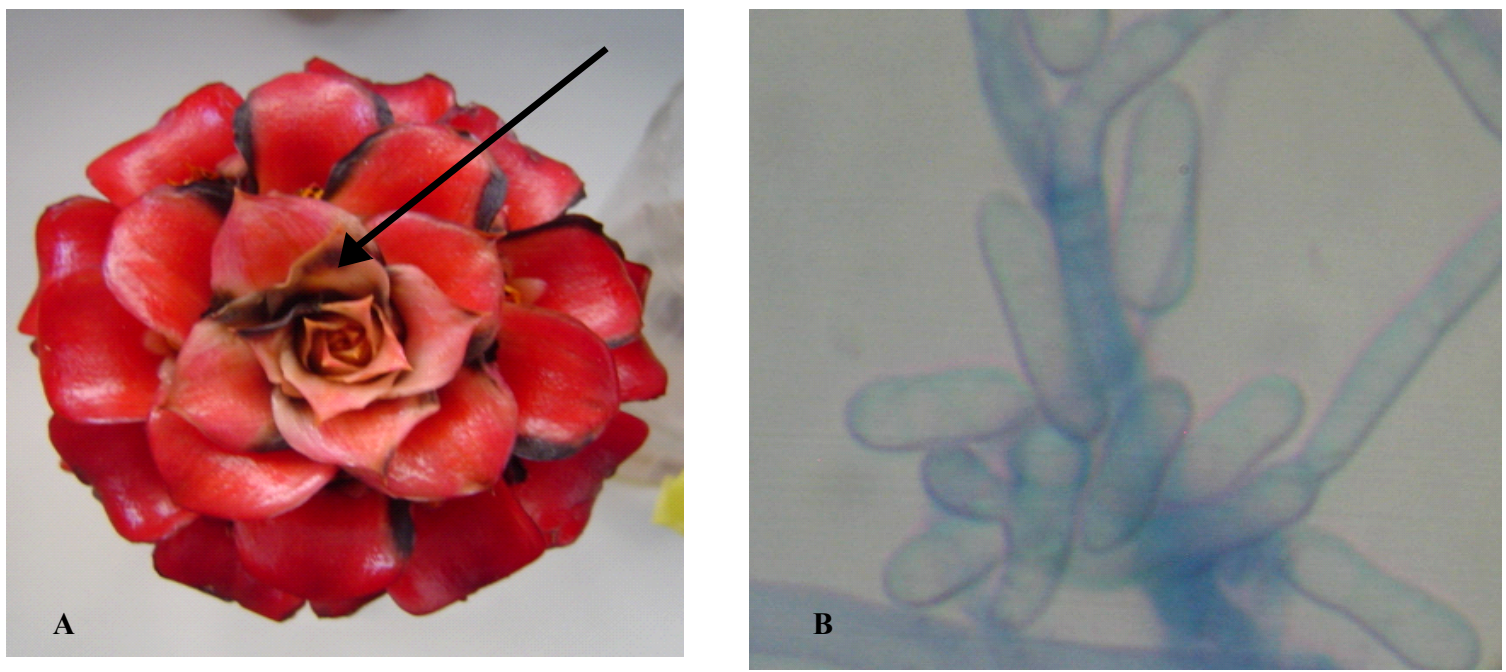

Figura 1. A- Sintomas de Colletotrichum gloeosporioides em inflorescências de Tapeinochilos ananassae e B- Conídios de C. gloeosporioides. 